\title{
Community-acquired antibiotic resistance in urinary isolates from adult women in Canada
}

\author{
Warren J Mclsaac MD MSc CCFP ${ }^{1,3}$, Tony Mazzulli MD FRCP ${ }^{2,4}$, Joanne Permaul BScHons CCRP1, \\ Rahim Moineddin $\mathrm{PhD}^{3,5}$, Donald E Low MD FRCP2,4
}

WJ McIsaac, T Mazzulli, J Permaul, R Moineddin, DE Low. Community-acquired antibiotic resistance in urinary isolates from adult women in Canada. Can J Infect Dis Med Microbiol 2006;17(6):337-340.

BACKGROUND: There are currently limited data regarding the prevalence of antimicrobial-resistant organisms causing communityacquired urinary tract infections among adult women in Canada. Trimethoprim-sulfamethoxazole (TMP-SMX) is the recommended first-line empirical antibiotic treatment, unless resistance of Escherichia coli to TMP-SMX exceeds 20\%.

OBJECTIVE: To assess current levels of TMP-SMX-resistant E coli in community-acquired cases of urinary tract infection in adult women. METHOD: Assessment of urine culture reports obtained from 21 laboratories across Canada, submitted by family physicians for women aged 16 years and older.

RESULTS: In 2199 adult women with a positive urine culture, $1079(49.1 \%)$ of pathogens isolated were resistant to at least one antibiotic and $660(30.0 \%)$ were multidrug-resistant (resistant to two or more antibiotics). TMP-SMX resistance was seen in 245 of 1613 (15.2\%) E coli isolates (95\% CI 13.5 to 17.0 ). This proportion was higher in women 50 years of age and older (155 of 863 isolates [18.0\%]; $\mathrm{P}=0.001$ ), in British Columbia (70 of 342 isolates [20.5\%]) and in Ontario (62 of 370 isolates [16.8\%]) when compared with eastern provinces ( 65 of 572 isolates [11.4\%]; $\mathrm{P}=0.001$ ). Fluoroquinoloneresistant E coli occurred in 107 of 1557 (6.9\%) isolates (95\% CI 5.7 to 8.2), with the highest level found in British Columbia (54 of 341 isolates [15.8\%]; $\mathrm{P}=0.001$ )

CONCLUSION: TMP-SMX continues to be appropriate as firstline empirical treatment of acute cystitis in adult women in Canada, as resistance remains below 20\%. However, TMP-SMX resistance is higher in older women and in some provinces. The level of fluoroquinolone-resistant E coli is highest in British Columbia.

\section{Une antibiorésistance non nosocomiale dans les isolats urinaires de femmes canadiennes}

\begin{abstract}
HISTORIQUE : Les données sur la prévalence des organismes résistants aux antimicrobiens provoquant des infections urinaires non nosocomiales chez les femmes du Canada sont limitées. Le triméthoprimsulfaméthoxazole (TMP-SMX) est le traitement antibiotique empirique de choix recommandé, à moins que la résistance de l'Escherichia coli au TMPSMX soit supérieure à $20 \%$.

OBJECTIF : Évaluer les taux courant d'E coli résistant au TMP-SMX en cas d'infections urinaires non nosocomiales chez les femmes.

MÉTHODOLOGIE : L'évaluation des résultats de cultures urinaires obtenues dans 21 laboratoires du Canada, soumises par les médecins de famille de femmes de 16 ans et plus.

RÉSULTATS : Chez 2199 femmes ayant une culture urinaire positive, $1079(49,1)$ des pathogènes isolés étaient résistants à au moins un antibiotique et 660 (30,0\%) étaient multirésistants (résistants à au moins deux antibiotiques). On observait une résistance au TMP-SMX dans 245 des $1613(15,2 \%)$ isolats à l'E coli (95\% IC 13,5 à 17,0). Cette proportion était plus élevée chez les femmes de 50 ans et plus (155 isolats sur $863[18,0 \%] ; P=0,001$ ), en Colombie-Britannique (70 isolats sur 342 [20,5\%]; $\mathrm{P}=0,001)$ et en Ontario (62 isolats sur 370 [16,8 \%]) par rapport aux provinces atlantiques (65 isolats sur 572 [11,4\%]; $\mathrm{P}=0,001$ ). On observait un $E$ coli résistant à la fluoroquinolone dans 107 des 1557 (69,9\%) isolats (95\% IC 5,7 à 8,2), le taux le plus élevé s'observant en Colombie-Britannique (54 des 341 isolats [15,8 \%]; $\mathrm{P}=0,001$ ).

CONCLUSION : Le TMP-SMX continue de convenir comme traitement empirique de choix de la cystite aiguë chez les femmes du Canada, car la résistance demeure inférieure à $20 \%$. Cependant, la résistance au TMP-SMX est plus élevée chez les femmes plus âgées et dans certaines provinces. Le plus haut taux d'E coli résistant à la fluoroquinolone s'observe en Colombie-Britannique.
\end{abstract}

Key Words: Antibiotic resistance; Primary care; Uropathogens

\begin{abstract}
three-day course of trimethoprim-sulfamethoxazole (TMPA $\mathrm{SMX}$ ) is recommended as first-line empirical treatment for acute cystitis in adult women in North America, where resistance of Escherichia coli to TMP-SMX is less than 20\% (1,2). TMP-SMX resistance has increased over time $(3,4)$, with a resulting shift toward the use of other antibiotics for acute cystitis, including fluoroquinolones $(5,6)$. There is concern that this may promote the more rapid emergence of fluoroquinoloneresistant uropathogens and reduce the effectiveness of fluoroquinolones in treating more serious infections $(7,8)$.
\end{abstract}

Trying to determine the rate of TMP-SMX resistance in community-acquired cases of acute cystitis has been problematic. Widely varying rates of resistance have been reported in different countries (9) and from different regions within the same country (4). In Canada, a study of outpatients attending tertiary care hospitals found that $19 \%$ of E coli isolates were resistant to TMP-SMX; however, the study included men and children (10). Two other community-based studies found that $8 \%(11)$ and $11 \%$ (12) of E coli isolates were resistant to TMPSMX. We conducted a national study of community-acquired

\footnotetext{
${ }^{1}$ Department of Family Medicine; ${ }^{2}$ Department of Microbiology, Mount Sinai Hospital; ${ }^{3}$ Department of Family and Community Medicine;

${ }^{4}$ Department of Laboratory Medicine and Pathobiology; ${ }^{5}$ Department of Public Health Sciences, University of Toronto, Toronto, Ontario

Correspondence and reprints: Dr Warren J McIsaac, Mount Sinai Family Medicine Centre, 600 University Avenue, Room 413, Toronto, Ontario

M5G 1X5. Telephone 416-586-3190, fax 416-586-3175, e-mail wmcisaac@mtsinai.on.ca

Received for publication January 16, 2006. Accepted June 8, 2006
} 


\begin{tabular}{|c|c|c|c|}
\hline Characteristic & $\mathbf{n}$ & Any resistance & $\%$ \\
\hline Total & 2199 & 1079 & 49.1 \\
\hline \multicolumn{4}{|l|}{ Age } \\
\hline $16-49$ years & 928 & 392 & 42.2 \\
\hline $50-64$ years & 409 & 204 & 49.9 \\
\hline$\geq 65$ years & 862 & 483 & $56.0^{*}$ \\
\hline \multicolumn{4}{|l|}{ Region } \\
\hline British Columbia & 451 & 238 & 52.8 \\
\hline Western provinces $^{\dagger}$ & 367 & 186 & 50.7 \\
\hline Ontario & 498 & 246 & 49.4 \\
\hline Eastern provinces ${ }^{\ddagger}$ & 802 & 361 & $45.0 \S$ \\
\hline
\end{tabular}

${ }^{*} P<0.001$; †Saskatchewan and Manitoba; $¥$ New Brunswick, Nova Scotia, Prince Edward Island and Newfoundland; $\$ P=0.045$

urinary tract infections to update TMP-SMX resistance rates and determine whether resistance was sufficiently high in some regions to warrant changes to empirical treatment recommendations.

\section{METHODS}

Canadian laboratories providing microbiology services were contacted by mail in 2004 . Some laboratories had participated in a previous study (12), while others were identified from Health Canada and Internet listings of commercial laboratories. A faxback form was provided to indicate interest in participation or a request for additional information. Two follow-up reminder letters were sent to nonresponders.

Each laboratory was asked to provide 100 recent urine culture and susceptibility reports positive for significant bacterial growth by their usual criteria. They were asked to limit reports to those submitted from family physicians' offices, and to exclude nursing homes, hospitalized patients and hospital outpatient departments. Only one report per patient was included. The culture report provided the patient age, sex, and city and province of residence. Where no patient address was provided, the laboratory address was used. Patient names were removed from reports. The organism, colony count and antibiotic susceptibility was determined from the reports. Organisms with intermediate susceptibility were considered susceptible. The analysis was limited to adult women 16 years of age and older.

Categorical variables were described using frequencies and compared with $\chi^{2}$ testing (STATA Release 6.0, StataCorp, USA). A wide range of oral and parenteral antibiotic susceptibilities were reported. Antimicrobial resistance were determined to be 'any resistance' (resistance to at least one antibiotic reported) or 'multidrug resistance' (resistance to two or more antibiotics reported). In assessing regional differences, the analysis was limited to four antibiotic classes (ampicillin, TMP-SMX, fluoroquinolones and nitrofurantoin). Multiple logistic regression was used to control for age and other differences between regions. Ethics approval was obtained from the Mount Sinai Hospital Research Ethics Board.

\section{RESULTS}

Of the 43 laboratories contacted, 21 (48.8\%) provided urine culture reports for 2199 women from across Canada (Table 1). All cultures were obtained in 2004. The majority of reports were from Ontario, Nova Scotia and British Columbia. No reports were received from Alberta. Because of the small numbers of isolates from some provinces, adjacent provinces were grouped together into regions to examine regional variations in resistance. Quebec was excluded from the regional analysis because too few reports were received. Community-based laboratories provided all of the reports from Ontario, while hospital laboratories provided all of the reports from the eastern provinces. The mean age of women was 55.2 years (range 16 to 100 years), with most women older than 50 years of age.

The most common organisms isolated were E coli (1634 [74.3\%]), Klebsiella pneumoniae (156 [7.1\%]), Proteus mirabilis (82 [3.7\%]) Enterocococcus species (70 [3.2\%]) and Staphylococcus saprophyticus (20 [0.9\%]). The remaining $237(10.8 \%)$ isolates included Acinetobacter, Citrobacter, Enterobacter and group B streptococcus. Almost one-half of isolates were resistant to at least one antibiotic, while $660(30.0 \%)$ were multidrug-resistant. Ampicillin resistance was most common (842 of 2107 isolates [40.0\%]), followed by resistance to TMP-SMX (293 of 2069 isolates [14.2\%]), cefazolin (121 of 1314 isolates [9.2\%]), nitrofurantoin (187 of 2124 isolates [8.8\%]) and fluoroquinolones (130 of 2069 isolates [6.3\%]).

Resistance increased with age, and there was a trend toward higher levels of antibiotic resistance in the western provinces $(\mathrm{P}=0.045)$. Multidrug resistance was highest in British Columbia (170 of 451 [37.7\%]) compared with the rest of Canada (465 of 1667 isolates [27.9\%]; $\mathrm{P}<0.001$ ). After adjusting for differences in patient age and organism distribution among the regions, antibiotic resistance remained higher in British Columbia (adjusted OR 1.30, 95\% CI 1.03 to 1.63) than in other regions, as did multidrug resistance (adjusted OR $1.60,95 \%$ CI 1.28 to 1.99 ).

\section{E coli antibiotic resistance}

There were 610 of 1634 (37.3\%) E coli isolates resistant to at least one antibiotic and 415 of 1634 (25.4\%) resistant to two or more antibiotics. Ampicillin resistance was reported in 512 of 1615 isolates (31.7\%; 95\% CI 29.4 to 34.0 ), 245 of 1613 isolates $(15.2 \%$; $95 \%$ CI 13.5 to 17.0$)$ were resistant to TMP-SMX, 107 of 1557 isolates (6.9\%; 95\% CI 5.7 to 8.2) were resistant to fluoroquinolones, 53 of 1025 isolates (5.2\%; 95\% CI 3.9 to 6.7) were resistant to cefazolin, and 22 of 1614 isolates (1.4\%; $95 \%$ CI 0.9 to 2.1 ) were resistant to nitrofurantoin. Because the level of ciprofloxacin-resistant E coli (100 of 1385 [7.2\%]) was similar to overall fluoroquinolone resistance $(\mathrm{P}=0.71)$, the latter was used in further analyses to make use of all available data.

Regional variations in E coli antibiotic resistance were found for TMP-SMX and fluoroquinolones (Table 2). TMPSMX resistance reached the 20\% threshold (suggested by the Infectious Diseases Society of America for consideration of alternative first-line agents for empirical treatment [1]) in British Columbia, and approached this level in Ontario. TMPSMX-resistant $E$ coli were also more common in women 50 to 64 years of age (52 of 291 [17.9\%]) and in those 65 years of age and older (103 of 572 [18.0\%]) when compared with younger women ( 90 of 750 [12.0\%]; $\mathrm{P}=0.004$ ). Adjusting for age differences among regions did not affect the results. TMP-SMX resistance remained higher in British Columbia (adjusted OR 1.94, 95\% CI 1.34 to 2.81) and Ontario (adjusted OR 1.61, $95 \%$ CI 1.10 to 2.35 ) than in the eastern provinces. 
TABLE 2

Regional variations in Escherichia coli antibiotic resistance in community-acquired urinary tract infections in Canada

\begin{tabular}{cccccc}
\hline Resistance & $\begin{array}{c}\text { British } \\
\text { Columbia }\end{array}$ & $\begin{array}{c}\text { Western } \\
\text { provinces }\end{array}$ & Ontario & $\begin{array}{c}\text { Eastern } \\
\text { provinces }\end{array}$ & $\mathbf{P}$ \\
\hline Any resistance, & 143 of 342 & 105 of 269 & 146 of 371 & 189 of 592 & 0.01 \\
$\mathrm{n}(\%)$ & $(41.8)$ & $(39.0)$ & $(39.4)$ & $(31.9)$ & \\
$\begin{array}{c}\text { Multidrug } \\
\text { resistance, } \mathrm{n}(\%)\end{array}$ & 102 of 342 & 55 of 269 & 92 of 371 & 150 of 592 & 0.07 \\
Antibiotic-specific & $(29.8)$ & $(20.5)$ & $(24.8)$ & $(25.3)$ & \\
resistance, $\mathrm{n}(\%)$ & & & & & \\
Ampicillin & 113 of 342 & 84 of 269 & 132 of 371 & 159 of 573 & 0.07 \\
& $(33.0)$ & $(31.2)$ & $(35.6)$ & $(27.8)$ & \\
TMP-SMX & 70 of 342 & 35 of 269 & 62 of 370 & 65 of 572 & 0.001 \\
& $(20.5)$ & $(13.0)$ & $(16.8)$ & $(11.4)$ & \\
Fluoroquinolones & 54 of 341 & 7 of 216 & 26 of 368 & 17 of 572 & $<0.001$ \\
& $(15.8)$ & $(3.2)$ & $(7.1)$ & $(3.0)$ & \\
Nitrofurantoin & 8 of 342 & 1 of 269 & 5 of 371 & 8 of 572 & 0.24 \\
& $(2.3)$ & $(0.4)$ & $(1.4)$ & $(1.4)$ & \\
\hline
\end{tabular}

TMP-SMX Trimethoprim-sulfamethoxazole

Regional variations in fluoroquinolone resistance were also seen, with significantly higher levels of resistance in British Columbia $(\mathrm{P}<0.001)$. Fluoroquinolone resistance increased with age, with 22 of 712 (3.1\%) E coli isolates resistant to fluoroquinolones in women 16 to 49 years of age, 20 of 283 $(7.1 \%)$ isolates in women 50 to 64 years of age, and 65 of 562 $(11.6 \%)$ isolates in women 65 years of age and older $(\mathrm{P}<0.001)$. Resistance ranged from a low of $1.1 \%$ (three of 267) in women 16 to 49 years of age in eastern provinces to a high of $24.3 \%$ (36 of 148) in women 65 years of age and older from British Columbia $(\mathrm{P}<0.001$; Fisher's exact test). Results were similar when the analysis was repeated using ciprofloxacin instead of all fluoroquinolones. After controlling for age, fluoroquinolone resistance remained higher in British Columbia than elsewhere in Canada (adjusted OR 3.88, 95\% CI 2.57 to 5.84 ).

Although culture reports came from 18 different communities in British Columbia, $80 \%$ came from two communities. The rate of fluoroquinolone-resistant $E$ coli was lower in the two communities (38 of 278 [13.7\%]) than in the remaining 16 communities combined (16 of 63 [25.4\%]; $\mathrm{P}=0.02$ ), indicating that the high rate of fluoroquinolone resistance in British Columbia was not due to a few communities with high resistance levels. To exclude the possibility that nursing home residents had been included, the analysis was repeated excluding women 65 years of age and older. Fluoroquinolone-resistant $E$ coli was also higher in women younger than 65 years of age in British Columbia (18 of 193 [9.3\%]) than in the western provinces (three of 138 [2.2\%]), Ontario (15 of 273 [5.5\%]) and the eastern provinces (four of $346[1.1 \%] ; \mathrm{P}<0.001$ ).

To assess whether $E$ coli resistance rates were increasing, the results were compared with a previous study (Table 3) (12). Women 50 to 64 years of age and those 65 years of age and older were combined due to small numbers in the earlier study. There were no significant differences by age or region in TMP. SMX-resistant E coli between the two time periods, although there was a trend toward increased TMP-SMX resistance overall. There was a significant increase in fluoroquinolone-resistant E coli overall and by region.
TABLE 3

Changes in community-acquired Escherichia coli antibiotic resistance between 2002 and 2004

\begin{tabular}{|c|c|c|c|}
\hline & $\begin{array}{l}\text { Previous study } \\
\text { (2002) (12) }\end{array}$ & $\begin{array}{c}\text { Current study } \\
\text { (2004) }\end{array}$ & $\mathbf{P}$ \\
\hline \multicolumn{4}{|l|}{ TMP-SMX, n (\%) } \\
\hline Any resistance & 20 of $183(10.9)$ & 245 of $1613(15.2)$ & 0.12 \\
\hline \multicolumn{4}{|l|}{ Age group } \\
\hline 16 to 49 years & 12 of $116(10.3)$ & 90 of $750(12.0)$ & 0.61 \\
\hline 50 years or older & 8 of 67 (11.9) & 155 of 863 (18.0) & 0.21 \\
\hline \multicolumn{4}{|l|}{ Region } \\
\hline Western Canada & 9 of $49(18.4)$ & 105 of $611(17.2)$ & 0.83 \\
\hline Eastern Canada & 11 of $132(8.3)$ & 127 of $942(13.5)$ & 0.10 \\
\hline \multicolumn{4}{|l|}{ Fluoroquinolone, n (\%) } \\
\hline Any resistance & 2 of $178(1.1)$ & 107 of 1557 (6.9) & $0.001^{*}$ \\
\hline \multicolumn{4}{|l|}{ Age group } \\
\hline 16 to 49 years & 0 of $107(0.0)$ & 22 of $712(3.1)$ & $0.10^{*}$ \\
\hline 50 years or older & 2 of $71(2.8)$ & 85 of $845(10.1)$ & $0.06^{*}$ \\
\hline \multicolumn{4}{|l|}{ Region } \\
\hline Western Canada & 0 of $52(0.0)$ & 61 of $557(11.0)$ & $0.006^{*}$ \\
\hline Eastern Canada & 1 of $124(0.8)$ & 43 of $940(4.6)$ & $0.052^{*}$ \\
\hline
\end{tabular}

${ }^{*}$ Fisher's exact test. TMP-SMX Trimethoprim-sulfamethoxazole

\section{DISCUSSION}

The Infectious Diseases Society of America has recommended TMP-SMX for the first-line empirical antibiotic treatment of acute cystitis, unless the level of TMP-SMX-resistant E coli in an area exceeds $20 \%$ (1). While the clinical relevance of this threshold has been questioned (8), treatment failure is more common in women with TMP-SMX-resistant $E$ coli (13). The present study found that $15 \%$ of $E$ coli isolates from adult women with community-acquired urinary tract infections in Canada are currently resistant to TMP-SMX. As a result, no changes in prescribing recommendations for Canadian physicians are needed at present.

There were some areas of the country and some age groups where E coli TMP-SMX resistance was higher. The level of TMP-SMX-resistant E coli in British Columbia was 20\%. This was not due to differences between British Columbia and other regions in terms of population age. TMP-SMX-resistant E coli was also common in women 65 years of age and older. The levels of TMP-SMX in these two groups are at, or are approaching, the threshold suggested by the Infectious Diseases Society of America for considering alternatives to TMP-SMX in the empirical treatment of acute cystitis. Ongoing monitoring will be needed to determine whether resistance levels increase further in these groups.

However, it is unclear whether TMP-SMX resistance in Canada has increased in community-acquired urinary tract infections in adult women. A study by Zhanel et al (10) found that $19 \%$ of $E$ coli isolates were TMP-SMX-resistant, but the sample included men and children. Separate results for adult women by age groups were not reported. A 1997 study of urinary tract isolates from family physicians' offices in southern Ontario found that $8.2 \%$ of E coli were TMP-SMX-resistant, but the age and sex of the population was not described (11). A comparison of the current study with our previous study of adult women (12) found some increase in TMP-SMX resistance, although the change was not statistically significant. In addition, there were differences in how cultures were obtained in the two studies. 
In our previous study (12), urine cultures were obtained from clinically diagnosed cases of acute uncomplicated cystitis, whereas the current study used pooled urine cultures submitted to laboratories without clinical information. A study of all urinary tract infections in women seen in general practice found that $27 \%$ had complicating factors (14). The occurrence of TMP-SMX-resistant E coli was two to three times more likely in these women. A study based in New Zealand (15) also found lower levels of TMP-SMX resistance in clinically assessed cases of uncomplicated urinary tract infection compared with pooled community laboratory specimens. Thus, the suggestion of higher TMP-SMX resistance in the present study may also have been due to the use of pooled cultures.

The increase in the rate of fluoroquinolone-resistant $E$ coli between the two time periods was significant. The level of fluoroquinolone-resistant $E$ coli was $7 \%$. This is higher than the levels of $1 \%$ to $1.8 \%$ reported in previous Canadian studies (10-12). We found that $10 \%$ of $E$ coli isolates were fluoroquinolone-resistant in women older than 65 years of age, and this level was found to be $16 \%$ in British Columbia. While we were not able to rule out that some nursing home patients were included in the sample, fluoroquinolone resistance was higher in British Columbia even in younger women.

Reasons for the high level of fluoroquinolone resistance in British Columbia were not identified. However, prescriptions for fluoroquinolone antibiotics in British Columbia increased by 44\% between 1996 and 2000 (16). Because prior fluoroquinolone exposure is a risk factor for fluoroquinolone resistance (17), changes in prescription practices in British Columbia in community-acquired urinary tract infections may have contributed to the higher level of resistance. If confirmed, prescribing restrictions may be needed to prevent further increases in fluoroquinolone-resistant $E$ coli.

Resistance of $E$ coli to nitrofurantoin has remained low over the years (8) and was also uncommon in the current study. However, physicians prescribe antibiotics empirically in acute cystitis before knowing the causative organism. We found that $9 \%$ of all isolates were resistant to nitrofurantoin overall. Greater use of this antibiotic has been suggested to limit fluoroquinolone use (8), but additional research has been recommended to address questions about overall effectiveness and safety $(1,2,8)$. Other alternatives include beta-lactam antibiotics, although they are generally considered to be less effective $(2,8)$.

The major limitation of the present study was the use of pooled laboratory specimens. However, this method has also been used in other studies that have provided estimates of antibiotic resistance levels in $E$ coli $(4,10,11)$. Although the use of pooled laboratory specimens may overestimate resistance levels (15), this provides greater confidence in the conclusion that the level of TMP-SMX-resistant $E$ coli in acute cystitis seen by family physicians in Canada is significantly less than $20 \%$.

\section{CONCLUSIONS}

TMP-SMX continues to be an appropriate first-line empirical antibiotic treatment for acute uncomplicated cystitis in adult women in Canada, as resistance levels remain below 20\%. The level of fluoroquinolone-resistant $E$ coli in communityacquired urinary tract infections should be monitored, and the apparent high levels of fluoroquinolone resistance in British Columbia should be confirmed to determine whether prescribing restrictions are warranted. Future studies should use urine cultures from clinically confirmed cases of acute uncomplicated cystitis to avoid overestimating resistance rates.

\section{REFERENCES}

1. Warren JW, Abrutyn E, Hebel JR, Johnson JR, Schaeffer AJ, Stamm WE. Guidelines for antimicrobial treatment of uncomplicated acute bacterial cystitis and acute pyelonephritis in women. Infectious Diseases Society of America (IDSA). Clin Infect Dis 1999;29:745-58.

2. Fihn SD. Clinical practice. Acute uncomplicated urinary tract infection in women. N Engl J Med 2003;349:259-66.

3. Gupta K, Scholes D, Stamm WE. Increasing prevalence of antimicrobial resistance among uropathogens causing acute uncomplicated cystitis in women. JAMA 1999;281:736-8.

4. Gupta K, Sahm DF, Mayfield D, Stamm WE. Antimicrobial resistance among uropathogens that cause community-acquired urinary tract infections in women: A nationwide analysis. Clin Infect Dis 2001;33:89-94

5. Carrie AG, Metge CJ, Zhanel GG. Antibiotic use in a Canadian province, 1995-1998. Ann Pharmacother 2000;34:459-64.

6. Huang ES, Stafford RS. National patterns in the treatment of urinary tract infections in women by ambulatory care physicians. Arch Intern Med 2002;162:41-7.

7. Bakken JS. The fluoroquinolones: How long will their utility last? Scan J Infect Dis 2004;36:85-92.

8. Hooton TM, Besser R, Foxman B, Fritsche TR, Nicolle LE. Acute uncomplicated cystitis in an era of increasing antibiotic resistance: A proposed approach to empirical therapy. Clin Infect Dis 2004;39:75-80.

9. Kahlmeter G; ECO.SENS. An international survey of the antimicrobial susceptibility of pathogens from uncomplicated urinary tract infections: The ECO.SENS Project. J Antimicrob Chemother 2003;51:69-76.

10. Zhanel GG, Karlowsky JA, Harding GK, et al. A Canadian national surveillance study of urinary tract isolates from outpatients: Comparison of the activities of trimethoprim-sulfamethoxazole, ampicillin, mecillinam, nitrofurantoin, and ciprofloxacin. The Canadian Urinary Isolate Study Group. Antimicrob Agents Chemother 2000;44:1089-92.

11. Mazzulli T, Skulnick M, Small G, et al. Susceptibility of community Gram-negative urinary tract isolates to mecillinam and other oral agents. Can J Infect Dis 2001;12:289-92.

12. McIsaac WJ, Mazzulli T, Moineddin R, Raboud J, Ross S. Uropathogen antibiotic resistance in adult women presenting to family physicians with acute uncomplicated cystitis. Can J Infect Dis Med Microbiol 2004;15:266-70.

13. Raz R, Chazan B, Kennes Y, et al; Israeli Urinary Tract Infection Group. Empiric use of trimethoprim-sulfamethoxazole (TMP-SMX) in the treatment of women with uncomplicated urinary tract infections, in a geographical area with a high prevalence of TMP-SMX-resistant uropathogens. Clin Infect Dis 2002;34:1165-9.

14. Hummers-Pradier E, Koch M, Ohse AM, Heizmann WR, Kochen MM. Antibiotic resistance of urinary pathogens in female general practice patients. Scand J Infect Dis 2005;37:256-61.

15. Richards DA, Toop LJ, Chambers ST, et al. Antibiotic resistance in uncomplicated urinary tract infection: Problems with interpreting cumulative resistance rates from local community laboratories. N Z Med J 2002;115:12-4.

16. Patrick DM, Marra F, Hutchison J, Monnet DL, Ng H, Bowie WR. Per capita antibiotic consumption: How does a North American jurisdiction compare with Europe? Clin Infect Dis 2004;39:11-7.

17. Killgore KM, March KL, Guglielmo BJ. Risk factors for communityacquired ciprofloxacin-resistant Escherichia coli urinary tract infection. Ann Pharmacother 2004;38:1148-52. 


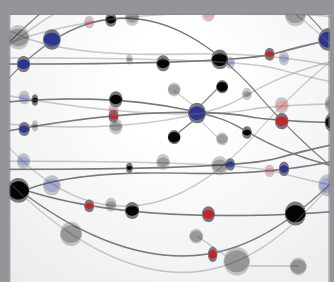

The Scientific World Journal
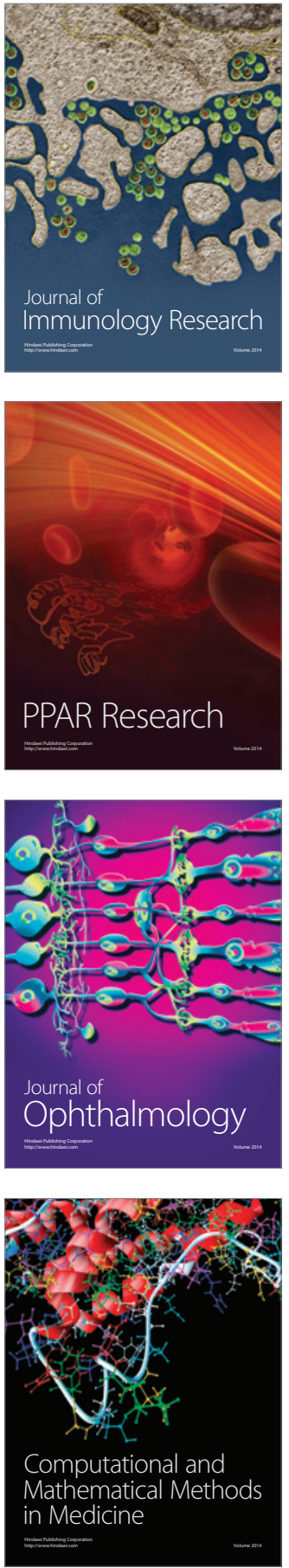

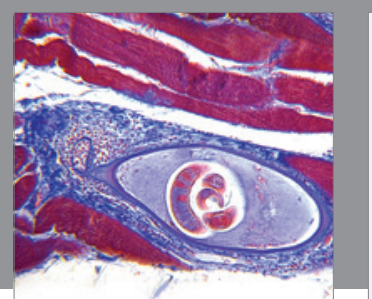

Gastroenterology Research and Practice

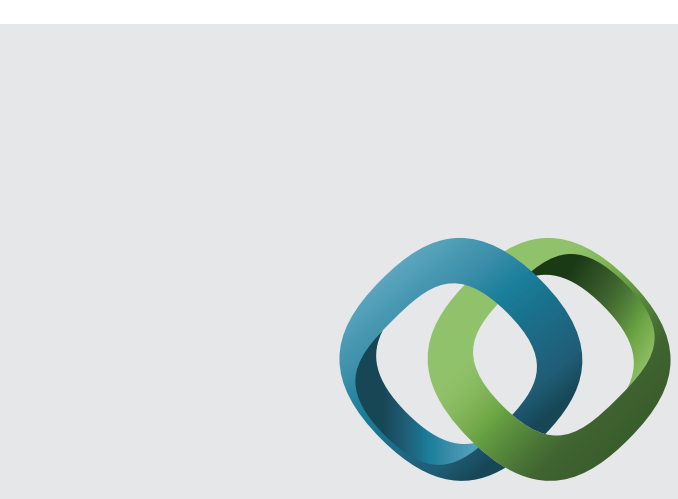

\section{Hindawi}

Submit your manuscripts at

http://www.hindawi.com
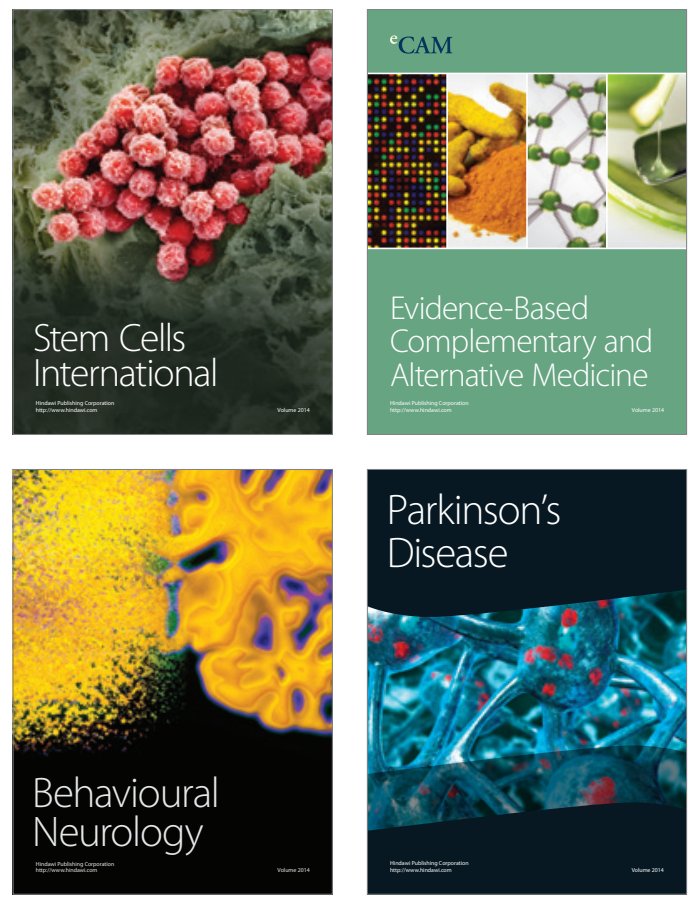
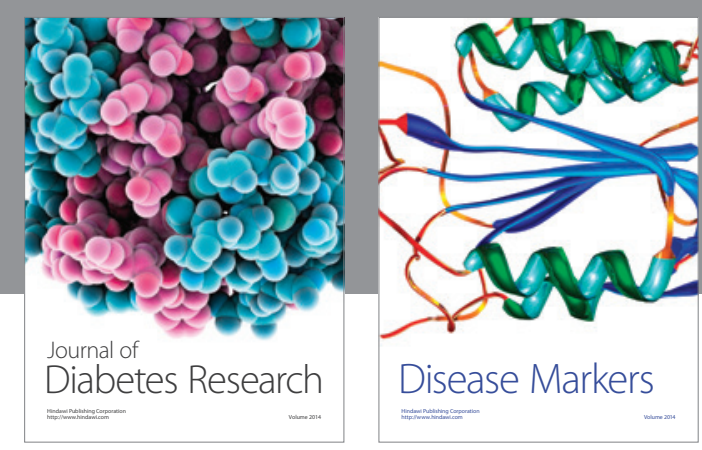

Disease Markers
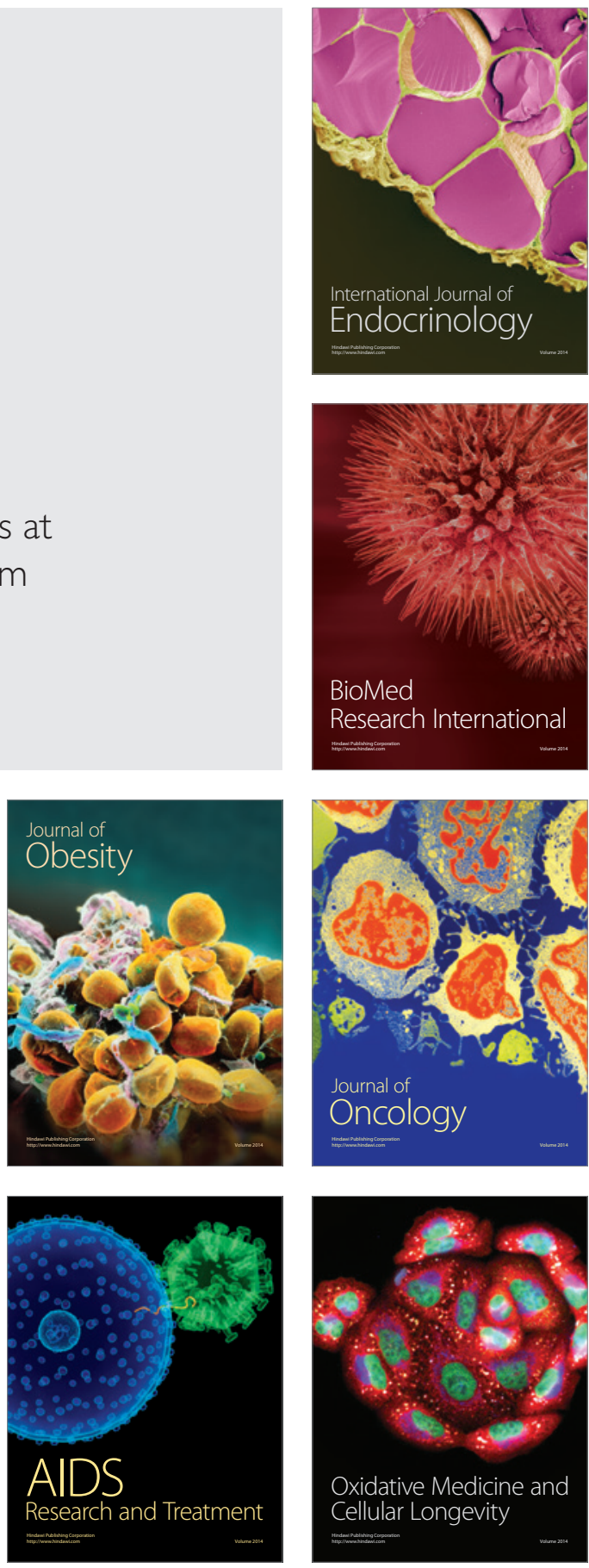